\title{
Análisis de mecanismos de participación local en Colombia: Audiencias de Rendición de Cuentas y Consejos Territoriales de Planeación ${ }^{1}$ Analysis of mechanisms of local participation in Colombia: Audiences of Accountability and Territorial Planning Councils
}

Recibido: 09 de octubre de 2015 - Revisado: 27 de mayo de 2016 - Aceptado: 22 de junio de 2016.

José Andrés Hernández Bonivento²

\section{Resumen}

El presente artículo busca analizar el diseño y la implementación de dos mecanismos institucionales destinados a promover la participación ciudadana a escala local en Colombia: las Audiencias de Rendición de Cuentas y los Consejos Territoriales de Planeación (CTP). Luego del análisis, que involucra un estudio comparativo de su implementación en dos municipios colombianos, se identifican deficiencias del diseño institucional de dichos mecanismos, que implican la necesidad de repensar y reformular dichas herramientas en la búsqueda por consolidar la participación ciudadana y mejorar las acciones gubernamentales en la esfera local colombiana.

\section{Palabras clave}

Participación ciudadana, rendición de cuentas, diseño institucional, Gobierno local, Colombia.

\begin{abstract}
This article aims to analyze the design and implementation of two institutional mechanisms to promote citizen participation at the local level in Colombia: Audiences for Accountability and Territorial Planning Councils (CTP). After the analysis, which involves a comparative study of its implementation in two Colombian municipalities, deficiencies in the institutional design of these mechanisms are identified, implying the need to rethink and reformulate these tools in the search to consolidate citizen participation and to improve government actions in the local Colombian sphere.
\end{abstract}

Keywords

Citizen participation, accountability, institutional design, Local government, Colombia.

\footnotetext{
${ }^{1}$ Artículo de investigación elaborado con información de la tesis: "Del gobierno a la gobernanza local: capacidades, instituciones y visiones de lo público en el proceso de descentralización en Colombia. Estudio de casos" presentada por el autor para optar al título de doctor.

2 Doctor en Ciencias Políticas y de la Administración por la Universidad Complutense de Madrid, España. Máster en Estudios Latinoamericanos por la Universidad de Salamanca, España. Actualmente es investigador y docente del Instituto Chileno de Estudios Municipales de la Universidad Autónoma de Chile.

Correo electrónico: jhernandez@ ichem.cl

Para citar este artículo use: Hernández, J. (2017). Análisis de mecanismos de participación local en Colombia: Audiencias de Rendición de Cuentas y Consejos Territoriales de Planeación. Civilizar Ciencias Sociales y Humanas, 17(32), 67-80. Doi: $10.22518 / 16578953.818$
} 


\section{Introducción}

Siguiendo casi una tendencia generalizada de reformas en la región, Colombia inicia desde comienzos de los años 90 la transferencia de competencias y recursos a sus entidades territoriales, con un especial énfasis en lo municipal, entendiendo la necesidad de involucrar los espacios locales en las decisiones que les competen. Dichas transferencias se establecieron bajo la lógica de incrementar la legitimidad política a través de elecciones locales y mecanismos de participación ciudadana, y mejorar las acciones estatales a través de un mayor conocimiento de las necesidades locales y una constante rendición de cuentas a la ciudadanía (Del Campo, 2006; Falleti, 2010; Grindle, 2007).

Estas reformas hacia la descentralización territorial, enmarcadas en la misma Constitución de 1991, generaron una serie de mecanismos que buscaron acercar el espacio público local a la ciudadanía, haciéndola partícipe de la regulación y la toma de decisiones de sus gobiernos municipales. Dos de ellos son las Audiencias Públicas de Control y Rendición de Cuentas y los Consejos Territoriales de Planeación (CTP). Al cumplirse 25 años de la Constitución, y sobre todo en el actual contexto de cambio institucional y posconflicto, se muestra necesario acercarnos a dichas instancias de interacción local para comprender cómo éstos han funcionado en la realidad, más allá de las buenas voluntades con las que fueron creadas.

Por lo mismo, y con el ánimo de aportar al debate actual, el objetivo general del presente texto es realizar un análisis de estos dos mecanismos institucionales de interacción social, instancias diseñadas para fomentar la participación y la rendición de cuentas en los municipios colombianos. Para ello, se busca observar tanto el diseño formal de dichas figuras como su implementación en contextos sociales disímiles, esperando establecer qué razones explicarían el desempeño de dichos mecanismos como espacios de gobernanza e interacción entre gobierno y ciudadanía.
Con esto en mente, el artículo se divide en tres secciones: en la primera, se establece el marco conceptual y el diseño metodológico de la investigación; una segunda parte desarrolla los resultados obtenidos a través del trabajo de campo, desarrollado en dos municipios colombianos de contextos sociopolíticos disímiles; la tercera y última sección busca esbozar algunas conclusiones y comentarios finales.

\section{Marco teórico y planteamiento del problema}

El tema de la participación ciudadana en la gestión pública no es nada nuevo, siendo América Latina el lugar de nacimiento de mecanismos novedosos (como lo fueron los presupuestos participativos) y de entramados institucionales que buscaron promover el involucramiento de la ciudadanía en el proceso y toma de decisiones. Esto tuvo una especial importancia para los municipios, espacios que por su proximidad ante las necesidades ciudadanas se entendían como ideales para la interacción colaborativa entre gobierno, administración pública y ciudadanía (Blanco \& Gomà, 2002; Campbell, 2003; Font, 2007). Pero dicha interacción no es vista como algo ideal solamente por sus implicaciones en la consolidación democrática y la construcción de ciudadanía, sino también como un esfuerzo por mejorar la acción estatal y mejorar la eficacia y eficiencia de las políticas públicas: en un espacio de diálogo e interacción constante, donde exista creación y retroalimentación de información que permita identificar problemas y diseñar soluciones colectivas, las decisiones públicas serán más sólidas, las metas mejor definidas y las acciones para alcanzarlos consensuadas y colaborativas (Brugué \& Gallego, 2007; Del Campo, 2006; Subirats, 2007).

Ahora, una cosa es lo que se busca en el diseño de los mecanismos de participación y otra lo que se alcanza en su implementación. Esta distancia entre el "ser" y el "deber ser" se nos muestra como un punto fundamental a observar, 
sobre todo cuando hablamos de mecanismos de participación, puesto que son espacios que buscan generar interacción y confianza entre los gobiernos y la ciudadanía. Por lo mismo, si dichos espacios se convierten en mecanismos no funcionales, pueden generar, por el contrario, una mayor distancia y desconfianza entre el ciudadano de a pie y su gobierno municipal. Cabe entonces la pregunta: ¿qué razones explicarían que un mecanismo, que busca promover la participación, se implemente de manera adecuada y alcance sus metas? Partiendo desde la teoría neo-institucionalista, dos hipótesis surgen como respuesta: la primera tendría que ver con el diseño del mecanismo; la segunda, por el contexto donde se implementa. Veámoslo más en detalle.

Para Douglas North (1993), las instituciones son, esencialmente, sistemas de incentivos que moldean el comportamiento humano. Dichos sistemas son complejos entramados que van desde la constitucionalidad y la legislación hasta las costumbres y tradiciones de una región específica, y su nivel de impacto dentro de la sociedad depende de la propia capacidad de aplicación y de generar sanciones (enforcement) de la misma. Por lo mismo, al interior de la sociedad pueden llegar a coexistir, paralelamente, dos tipos de "reglas del juego" que definen la vida en comunidad: las instituciones formales y las informales. Dichas reglas se dan de manera explícita, en el caso de las formales, a través de la legislación nacional, mientras que las informales se presentan a manera de tradiciones, códigos sociales y costumbres arraigadas en una determinada comunidad.

Helmke y Levitsky (2004) se acercan a esta doble normatividad de la sociedad, observando las posibles relaciones entre lo formal y lo informal así como sus efectos en el desarrollo de acciones públicas. Luego de observar algunos casos latinoamericanos, los autores concluyen que al existir complementariedad en las metas últimas que buscan alcanzar tanto lo formal como lo informal, dicha relación se consolida como virtuosa, mientras que si entran en com- petencia, buscando alcanzar metas distintas, las acciones públicas tenderían al fracaso. Implica esto entonces que los resultados de la implementación de cualquier acción estatal dependen tanto de su propio diseño formal (mecanismos, organismos y estrategias planteadas para alcanzar las metas y objetivos deseados) como del contexto social, político y cultural donde se implementan (Güemes \& Hernández-Bonivento, 2014). Por lo mismo, en aras de realizar una revisión de los mecanismos de participación ciudadana institucional, se nos muestra imprescindible observar tanto la formalidad como la informalidad, buscando detectar qué aspectos son determinantes para su desempeño. En esta vía enfocamos la presente investigación.

\section{Diseño institucional de los mecanis- mos de participación en Colombia.}

Luego de la Constitución de 1991, durante la década de los 90, se presenta en Colombia una inusitada proliferación de mecanismos institucionales de participación en todos los sectores y hacia una amplia diversidad de grupos poblacionales (jóvenes, minorías étnicas, etc.) que tuvieron especial importancia en la esfera local de gobierno. Tanto Ceballos y Martín (2001) como Velázquez y González (2003) hacen un recuento de dicha explosión de instancias formales, aunque también recalcan la debilidad de los espacios formales de participación dadas cinco características que parten desde su propio diseño institucional (Velázquez \& González, 2003):

(1) Todos los espacios surgen como mecanismos "de arriba hacia abajo" (top-down), diseñados por parte del gobierno y no como mecanismos de base; (2) las exigencias para participar en dichos espacios prefiguran al sujeto participante, sin recoger las dinámicas preexistentes; (3) los alcances de dichos espacios son limitados desde su propio diseño institucional, siendo espacios consultivos no vinculantes; (4) se establecen los mismos mecanismos para todo el territorio, sin tener en cuenta el contexto en el que se implementarían; 
(5) y las instancias del gobierno tienen un peso significativo y fundamental en su promoción y desarrollo.

Estas cinco características, generalizadas en el diseño de los mecanismos de participación, implican una asimetría de inicio en las relaciones entre los gobiernos locales y la ciudadanía, limitando su potencial impacto en la forma en que se toman decisiones a nivel local. Se convierten entonces en mecanismos más de información y consulta que de involucramiento o empoderamiento ciudadano, y en extremo dependientes de la voluntad política del gobernante local de turno. Dicha situación no se modifica de manera trascendental con la legislación posterior, ni siquiera con la nueva Ley Estatutaria de Participación Democrática (Ley 1757 de 2015), la cual buscó renovar el marco jurídico de dichos espacios y marcando prerrogativas formales de uso e implementación (así como la reglamentación de los nuevos cabildos abiertos), aunque sin acabar con las asimetrías institucionales para el involucramiento ciudadano y manteniendo cierta dispersión institucional al no derogar la anterior ley de participación de 1994 (Misión de Observación Electoral-MOE, 2015). Vemos entonces que el mismo diseño de los mecanismos de participación ciudadana en la gestión pública tiende hacia una visión consultiva e informativa, mas no deliberativa, y suelen ser dependientes de voluntades políticas locales para su funcionamiento y potencial incidencia en la toma de decisiones.

\section{Contexto e implementación: diseño de la investigación.}

Para observar la implementación de dichos mecanismos, se buscó recolectar información que fuera comparable entre casos que, aun teniendo un mismo marco legal institucional, fueran esencialmente distintos en cuestiones sociales, económicas, culturales y políticas, al mismo tiempo que contaran con resultados divergentes en cuanto a desempeño democrático y administrativo. Teniendo en cuenta datos de entidades oficiales (DANE y DNP), así como de organizaciones sociales (Transparencia por Colombia, Misión de Observación Electoral, Colombia Líder), y centrándonos en los municipios de tamaño medio (categorías tercera y cuarta), se seleccionaron los casos de Facatativá (Cundinamarca) y Ciénaga (Magdalena). En la tabla 1 se resumen los datos comparativos entre los casos seleccionados.

Tabla 1

Datos comparativos de municipios seleccionados

\begin{tabular}{|lll}
\hline Categoría & \multicolumn{1}{c}{ Facatativá (Cundinamarca) } & \multicolumn{1}{c}{ Ciénaga (Magdalena) } \\
\hline Población & Tercera (2009) & Cuarta (2009) \\
\hline Certificaciones & $119.849(2010)$ & $103.066(2010)$ \\
\hline Ingresos totales (2000) & Salud y educación & Salud y educación \\
\hline Ingresos totales (2010) & 16.910 millones COP* & 12.719 millones COP \\
\hline \% Población NBI* (1993) & 71.974 millones COP* & 101.805 millones COP \\
\hline \% Población NBI* (2010) & 21,66 & 52,72 \\
\hline Promedio IDM* 2007-2010 & 13,09 & 43,81 \\
\hline ITM* 2008-2009 & 85,29 & 50,62 \\
\hline Otros & 75,1 (Riesgo moderado) & 39,7 (Riesgo muy alto) \\
\hline
\end{tabular}

Fuentes: elaboración propia con base en Departo Administrativo Nacional de Estadísticas-DANE (2010), Departamento Nacional de Planeación -DNP (2010), Transparencia por Colombia, (2010), Misión de Observación Electoral -MOE (2011) y Colombia Líder, (2011). *COP: Pesos colombianos; NBI: Población con Necesidades Básicas Insatisfechas; IDM: Índice de Desempeño Municipal; ITM: Índice de Transparencia Municipal. 
Se observa entonces que a pesar de similitudes tanto en población como en presupuestos y competencias en salud y educación, los dos casos se muestran casi opuestos en materia de desempeño municipal, transparencia y riesgo frente a delitos electorales.

Siendo nuestro objetivo observar si el contexto influye en la implementación de los mecanismos de participación y rendición de cuentas, buscando observar tanto lo formal como lo informal de ambos casos, se diseñó una investigación de carácter cualitativo que permitiera acercarnos a la manera como estos mecanismos de interacción son concebidos y desarrollados en cada uno de los territorios. Durante la investigación se realizaron 37 entrevistas semiestructuradas, de las cuales 7 fueron a expertos en descentralización $\mathrm{y}$ miembros del gobierno nacional, 14 fueron a funcionarios o exfuncionarios públicos de ambas alcaldías, y 16 a miembros de organizaciones de la sociedad civil (ver anexo 1). Se seleccionan a su vez dos mecanismos fundamentales de participación institucional y rendición de cuentas para la comparación entre ambos municipios: las Audiencias Públicas de Control y Rendición de Cuentas y los Consejos Territoriales de Planeación. El trabajo de campo se realizó en marzo y abril del año 2012, en el marco de nuestra investigación doctoral.

\section{Resultados obtenidos}

\section{Audiencias Públicas de Control y Rendición de Cuentas.}

Las Audiencias Públicas, figuras creadas en la Constitución de 1991 y reseñadas en el artículo 33 de la Ley 489 de 1998, son mecanismos de control ciudadano en donde el gobierno local presenta la evaluación interna de sus acciones de política pública, buscando una mayor interacción con la comunidad y un acercamiento de la administración a la ciudadanía. La idea esencial de estas audiencias está en la información de los gastos y la presentación de resultados ante la ciudadanía, en aras de establecer una evaluación constante de las acciones de los gobiernos municipales.

Durante la investigación se preguntó a los entrevistados sobre sus percepciones alrededor de dichas figuras, y la imagen expresada por ellos fue, en ambos casos y de manera generalizada, muy negativa. Tanto en Facatativá como en Ciénaga se entienden como mecanismos viciados, que son más formales que cualquier otra cosa y que, en ocasiones, son abiertamente manipulaciones políticas y trampas de negociación entre redes clientelares. Aunque todos mantienen la necesidad de rendir cuentas como ejercicio fundamental de la democracia, estos mecanismos son vistos como solo forma, y nada de contenido, dejando una sensación más de manipulación que de rendición de cuentas.

En el caso de Facatativá, los comentarios iban más dirigidos al exceso de formalismo en la entrega de resultados, a las posibilidades de manipulación de datos, y a la monotonía y falta de interés que dichos ejercicios generan en la sociedad civil. De manera general, todos consideraban estos mecanismos como vacíos de sustancia, con datos poco verificables y sin ningún tipo de relevancia ante la comunidad. Se evidencia una crítica general de ser un espacio donde se mostraban muchos productos (outputs) pero no así impactos (outcomes) de las políticas, lo cual genera desconfianza y rechazo por parte de la ciudadanía, así como la percepción de un uso instrumentalizado de estos espacios de interacción por ambas partes: para los funcionarios, los espacios son utilizados por grupos de presión que solo buscan obtener beneficios sobre sus intereses más que un bienestar de la comunidad; para los miembros de organizaciones civiles, son plataformas donde la alcaldía busca darse un baño de legitimidad para luego hacer lo que más les interese, sin tener en cuenta la participación de la ciudadanía.

"En el tema que nos atañe, de salud o desarrollo social, es más difícil medir las cosas, porque a veces se invierten grandes cantidades 
de dinero, pero difícilmente se logra el objetivo; y a veces las rendiciones de cuentas son demasiado técnicas para mi gusto. Yo puedo rendir cuentas frente a cuánta población asegure, pero no a cuántos de esos asegurados se les prestó servicio con criterios de calidad, que es lo que queremos buscar. Entonces por eso, a veces, las rendiciones de cuentas terminan siendo un saludo a la bandera" (Comunicación personal no.19, 21 de marzo, 2012).

"Digamos que, como ciudadano y como conocedor de los informes de gestión, hay cosas que, de pronto, se manejaron con un síndrome de realidad de un cincuenta por ciento, y el otro cincuenta por ciento no era real, es decir, que para sacar los porcentajes se tenían en cuenta cosas que no se habían realizado" (Comunicación personal no.16, 20 de marzo, 2012, énfasis del autor).

"Monótonos y poco consecuentes. La rendición de cuentas de invertimos tantos millones $\mathrm{y}$ atendimos treinta y cinco mil personas, me parece que eso a uno como ciudadano, me deja como un poco confundida; porque yo digo: si atendieron al programa de niñez, por ejemplo, treinta y cinco mil niños en actividades recreativas, eso qué tan representativo es para mí municipio-" (Comunicación personal no.15, 15 de marzo de 2012).

Esta misma sensación de desconfianza entre los actores involucrados se evidencia en el caso de Ciénaga, donde según algunos entrevistados dichos eventos se convierten en escenarios de proselitismo y negociación abierta entre redes políticas. La rendición de cuentas es vista entonces como una obligación formal, dictada desde la lejana legislación nacional, que se utiliza para todo menos para mostrar una evaluación real de los avances y los impactos de las acciones de gobierno. Al mismo tiempo, entre los entrevistados se observaba una alta desconfianza ante los datos presentados, puesto que para muchos no se corresponden con la realidad. Al preguntar sobre este punto entre los funcionarios, dicha imagen parecía confirmarse: los modelos de manejo de información son muy deficientes y con cada cambio de Gobierno los procesos deben iniciar de cero, pues dada la alta movilidad en la planta la mayoría de los funcionarios se van de la alcaldía y se llevan toda la información. Esta apropiación de lo público se encuentra tan arraigado en el colectivo que nadie lo considera algo extraño, sino como algo "típico de la región".

"Son instancias de manipulación; se pueden prestar para la manipulación por parte de quien está obligado a rendir cuentas, que es el funcionario público en sus diferentes instancias de Gobierno (...) entonces, si hay una sociedad civil débil, la rendición de cuentas podría ser manipulable" (Comunicación personal no.24, 4 de abril de 2012, énfasis del autor).

"Tuve la oportunidad de asistir a la última que hizo el [alcalde saliente]. La hizo en el Teatro Municipal, hasta fue graciosa porque terminó con brindis, terminó con mariachis, con canto, con celebraciones, yo no, yo no... no estaba preparado para ver eso. Estaba preparado para ver una rendición pública de cuentas, a ver cuánto ingresó, cuánto gastó y qué invirtió, pero al final lágrimas y abrazos" (Comunicación personal no.26, 9 de abril, 2012, énfasis del autor).

"Sí, hay rendición de cuentas, pero como te digo, los sectores de interés ya se saben cuáles son; los equilibrios están perfectamente ordenados entre opositores y benefactores; entonces, simplemente esos ejercicios son una forma de mantener los estatutos o de movilizar los intereses... no pasa nada allí" (Comunicación personal no.28, 11 de abril, de 2012, énfasis del autor).

Aunque en distintos niveles, tanto en el caso de Facatativá como en el de Ciénaga existen críticas profundas a la formalidad de los mecanismos de rendición de cuentas, los cuales se prestan para la manipulación política y para dar un aire democrático por medio de informes cerrados y poco transparentes. Vemos entonces que su uso iría en contrasentido con la esencia de una gobernanza democrática local: no tienen una inclusión real de la ciudadanía, la cual se muestra apática ante dichos eventos; no logra entregar información real de manera horizontal con los grupos sociales, de manera 
que pueda existir una interacción informada y una colaboración por el bien de la comunidad; y lejos de intentar convertirse en mecanismos de evaluación de impactos, se instalan en una cómoda zona donde entregan datos fácilmente manipulables dada la asimetría de poderes interna. Lo observado durante la investigación es un descrédito total de estos mecanismos, generando efectos perversos: una creciente desconfianza ante mecanismos que buscaban acercar la administración a la comunidad.

\section{Planeación participativa: los Con- sejos Territoriales de Planeación (CTP).}

Creados por el artículo 340 de la Constitución de 1991, y regladas por la Ley 152 de 1994 y la Ley 388 de 1997, los CTP son cuerpos colegiados de carácter consultivo, que actúan como instancias de discusión en el proceso de planeación del Gobierno local. Éstos se encuentran conformados por particulares y representantes de las entidades territoriales, recogiendo miembros de los distintos sectores productivos, minorías étnicas y organizaciones sociales del municipio, en aras de analizar, discutir y coordinar el Plan de Desarrollo de sus territorios (Departamento Nacional de Planeación- DNP, 2007a).

Sus funciones dependen básicamente de la formulación del Plan de Desarrollo Municipal, documento que debe redactar el Gobierno local en los primeros meses de su administración y que se convertirá en la agenda de políticas del territorio. En un principio, los
CTP solo tenían relevancia en dicho periodo para después pasar a un letargo de cuatro años, pero en la Sentencia C-524 de 2003, la Corte Constitucional establece la importancia de que dicho órgano consultivo permanezca activo a lo largo de las administraciones, como mecanismo participativo de seguimiento y evaluación.

Pero las debilidades de dicho ejercicio se observan desde el propio diseño institucional de los CTP y se resumen en los siguientes puntos (remarcados, además, en las entrevistas realizadas):

Son instancias consultivas, esto es, sus iniciativas no tienen en ningún momento carácter vinculante para el gobierno municipal.

Los consejeros son elegidos mediante terna presentada al alcalde, quien en últimas toma la decisión de quién pertenece y quién no al CTP.

No cuentan con personería jurídica, por lo que no pueden obtener ningún tipo de financiación aparte de la que el municipio les preste.

Aunque la alcaldía está obligada a prestar apoyo para su funcionamiento (Ley 152 de 1994, art. 35), no existen sanciones por incumplimiento.

Durante el trabajo de campo, la gran mayoría de entrevistados que no hacían parte ni del gobierno local ni del CTP, desconocía de lleno dicha figura. Varios servidores públicos señalaron su desconocimiento sobre el tema, y algunos de los que sí conocían el CTP se mostraron abiertamente escépticos ante la funcionalidad de dicho organismo (tabla 2).

Tabla 2

Reconocimiento de los CTP por municipio y sector social

\begin{tabular}{|c|c|c|c|c|c|c|}
\hline Municipio & Sector & No conoce & $\begin{array}{c}\text { Conoce, imagen } \\
\text { positiva }\end{array}$ & $\begin{array}{c}\text { Conoce, imagen } \\
\text { negativa }\end{array}$ & Total & TOTAL \\
\hline \multirow{2}{*}{ Facatativá } & Servidor Público* & 3 & 3 & 2 & 8 & \multirow{2}{*}{14} \\
\hline & Sociedad Civil** & 6 & 0 & 0 & 6 & \\
\hline \multirow{3}{*}{ Ciénaga } & Servidor Público* & 1 & 2 & 3 & 6 & \multirow{2}{*}{12} \\
\hline & Sociedad Civil** & 4 & 2 & 0 & 6 & \\
\hline & TOTAL & 14 & 7 & 5 & & 26 \\
\hline
\end{tabular}

*Servidores en ejercicio o ex servidores públicos. **Organizaciones sociales que no pertenecían al CTP.

Fuente: elaboración propia. 
Ahora, una visión distinta se observó entre los consejeros del CTP entrevistados, quienes aun siendo conscientes de las debilidades de dicha figura se mostraban convencidos de la importancia de su trabajo y de la necesidad de dichos organismos. En el caso de Facatativá, todos los asistentes al CTP mostraron su desencanto con la figura del consejo por las razones antes mencionadas, pero consideraban que hacían un trabajo fundamental para el municipio. Su queja fundamental era el manejo de la información, a la cual no se sentían con el acceso adecuado, y a la baja influencia del CTP frente a la realidad del municipio. Ante esto último se hizo evidente el peso de la voluntad política del mandatario local, pues del alcalde depende si el trabajo de los CTP es tomado en cuenta o si hace caso omiso de todas sus recomendaciones:

"La información es asimétrica. Ellos tienen el periódico de hoy, nosotros el de ayer" (Comunicación personal no.9, 14 de marzo de 2012, énfasis del autor).

"Lo que ocurre es que si no hay voluntad administrativa o voluntad del alcalde, no pasa nada. El Consejo puede hacer muchas cosas, pero como es un órgano consultivo de aconsejar, de dar consejos, y pues la otra persona puede tomar o no el consejo" (Comunicación personal no.10, 14 de marzo de 2012, énfasis del autor).

En el caso de Ciénaga los entrevistados expresaron los mismos problemas señalados en el caso de Facatativá: un bajo impacto de sus decisiones, una muy alta dependencia de la voluntad del alcalde de turno, muchos problemas de funcionamiento $\mathrm{y}$, sobre todo, una gran diferencia entre lo que se presenta en la ley y lo que sucede en la realidad. Aun así, los entrevistados fueron muy positivos frente a las posibilidades del CTP, sobre todo como herramienta de movilización ciudadana. En tres entrevistas distintas fue narrada una pequeña batalla mantenida con el mandatario saliente por la denominación productiva del municipio, algo a lo que el CTP se negó, logrando ejercer la suficiente presión para que el alcalde y el Consejo Municipal descartaran la medida. Se menciona entonces que, aun con muchos problemas de diseño e implementación, la sola existencia de estos espacios puede marcar diferencias en la forma en que el Gobierno municipal y la comunidad interactúan, evitando en algunos casos arbitrariedades de parte de la alcaldía.

\footnotetext{
"Pues yo pienso que logramos posicionarnos en el contexto local como un cuerpo consultivo beligerante y que, en un momento determinado se le escuchó [...] Hoy, por lo menos, en la ciudad hay un reconocimiento de lo que es el Concejo Territorial, porque aquí no se sabía que era eso (risas)" (Comunicación personal no.30, 17 de abril de 2012).
}

Se observa entonces que los CTP se encuentran lejos de ser mecanismos de gobernanza local colaborativa, dada su alta dependencia a la voluntad de los alcaldes y con problemas de asimetría en cuanto a la información del municipio. Se presentan entonces como espacios formales que no conllevan incidencia automática en la vida municipal, pero que se han consolidado como espacios de reflexión entre actores sociales de distintos gremios, quienes hacen parte del Consejo. Este espacio de reflexión ha permitido una articulación social que no debe ser subvalorada, mucho menos cuando se presentan en espacios donde la interacción entre actores ha estado basada históricamente en clientelismos y la presencia de actores armados. Por lo mismo, es necesario remarcar la importancia fundamental de su existencia y focalizar los esfuerzos institucionales en cómo mejorar la interacción y el flujo de información entre los actores, base esencial de una verdadera gobernanza democrática a nivel local.

\section{Reflexiones finales y conclusiones}

A lo largo de los resultados de esta investigación se evidencian varias críticas generalizadas, tanto por parte de los servidores públicos como de las organizaciones sociales en los dos municipios seleccionados, frente a los mecanis- 
mos de interacción estudiados. A pesar de existir notorias diferencias entre los casos, son más evidentes las deficiencias comunes, lo cual se presenta como un llamado de atención para el diseño y la implementación de estos mecanismos institucionales de interacción social. Esta investigación arroja dos deficiencias fundamentales: la instrumentalización de la participación y la desconfianza entre los actores sociales.

Hablamos de instrumentalización de la participación cuando los actores sociales utilizan estos mecanismos no como espacios de debate y discusión, de toma de decisiones colectiva y de colaboración basada en el manejo de información compartida, sino como espacios de negociación política basada en intereses propios, intentando sacar el máximo provecho con el mínimo esfuerzo (Ruano, 2010). En las entrevistas se evidencia este uso inadecuado de los espacios de interacción por parte y parte, donde los miembros de organizaciones sociales ven los espacios como un "baño de legitimidad" de las administraciones sin que ellos tengan mayor influencia en lo que pasa realmente en el municipio, mientras los servidores públicos ven un uso particular y político de las organizaciones de dichos espacios, que buscan bloquear decisiones para obtener beneficios sobre sus propios intereses.

La situación antes descrita denota a su vez una gran desconfianza entre los actores sociales a nivel local. La percepción negativa que se manifiesta entre servidores públicos y sociedad civil, aun en espacios donde se ha presentado algún tipo de colaboración intersectorial, es evidente y general. Esto no necesariamente es malo, puesto que genera la necesidad de fiscalización y rendición de cuentas entre los actores involucrados, pero sí es negativo cuando impide el desarrollo de los mecanismos de interacción y de gobierno colectivo.

Ambas situaciones se presentan simultáneamente y son percibidas como cuestiones que se autoalimentan: dada la desconfianza entre actores, los mecanismos de participación son utilizados únicamente para sacar el mayor provecho de ellos, y dada la instrumentalización los actores pierden confianza en sus interlocutores y en el sistema mismo de participación. Se presenta entonces un círculo vicioso de la interacción local, basada en una preconcepción de la participación como una situación de sumacero: lo que gana uno lo pierde el otro. Dicha sensación de competencia constante hace que se pierda el sentido mismo de la participación ciudadana: la colaboración para alcanzar objetivos de común beneficio para las partes.

Vemos entonces que tanto las audiencias de rendición de cuentas como los CTP tienen defectos en sus diseños institucionales que impiden cumplir a cabalidad con las metas primarias con que fueron concebidas: la alta discrecionalidad con la que cuenta el alcalde y el Gobierno municipal sobre dichas instancias, su carácter consultivo y la poca fiscalización y seguimiento que existe del uso de dichos espacios, generan los incentivos necesarios para que dichos espacios caigan en la irrelevancia. Es para nosotros significativo que aun en contextos donde se esperaría un mejor desempeño de dichas instancias, éstas sean vistas como mecanismos fallidos, subrayando los problemas de diseño por encima de los contextuales. Partiendo de los resultados de la presente investigación, y buscando un acercamiento propositivo ante los mecanismos de participación ciudadana, quisiéramos a continuación señalar algunos puntos a tener en cuenta para el futuro:

\section{Manejo de la información:}

Una queja generalizada entre los entrevistados era la asimetría de información entre la ciudadanía y el Gobierno municipal. El manejo de la información pública es clave para los procesos de transparencia, participación y colaboración de los Gobiernos locales, por lo que es fundamental contar con datos específicos sobre el municipio que permita la interacción entre actores. Esto además es práctico para la alcal- 
día, puesto que la interacción genera nuevos conocimientos sobre la realidad de la población, lo que permite a su vez priorizar y focalizar esfuerzos tanto de la administración como de la colaboración entre sectores.

\section{Impactos, no productos:}

Otra queja generalizada es la calidad de la información que se presenta en los mecanismos de rendición de cuentas. Dichas evaluaciones suelen basarse en medición de productos más que de impactos, lo que deja la sensación de relleno y de una alta posibilidad de manipulación de la información presentada. La evaluación a partir de productos puede, a su vez, generar incentivos perversos, donde los Gobiernos locales se basen en un cumplimiento formal de las exigencias sin que esto conlleve a un verdadero cambio en la vida del municipio. Lógicamente es mucho más difícil hacer mediciones de impacto que de productos, pero es en esta vía donde habría que focalizar los esfuerzos.

\section{Involucrar a los actores en todo el proceso de toma de decisiones:}

Otra asimetría remarcada por los entrevistados fue el acceso al proceso de toma de decisiones, dada la naturaleza consultiva de la participación ciudadana. La percepción generalizada de los entrevistados participantes en estos espacios era la de asistir a eventos donde su opinión no sería tomada en cuenta. Pensemos entonces que cuando existen varios actores involucrados en la toma de decisiones, ésta se vuelve mucho más compleja, pero también más transparente, más consensuada y con mayor legitimidad (Brugué \& Gallego, 2007; Subirats, 2007).

\section{La necesidad de una "sombra de jerarquía":}

Por último, una mención recurrente fue la poca o nula fiscalización de dichos mecanismos. La fiscalización permanente genera la llamada "sombra de jerarquía" (Scharpf, 1994), esto es, la generación de incentivos que eviten el uso instrumentalizado de los espacios de participación y que, a su vez, genere la confianza fundamental para la interacción colaborativa. Los mecanismos pueden ser obligatorios, pero si no existe un seguimiento constante poco se puede esperar de su implementación.

Por último, se muestra necesario mencionar aspectos positivos observados en el desarrollo de la presente investigación. Lo más importante es que dichos espacios, por el solo hecho de existir, han generado movilización en la ciudadanía en ambos casos de estudio. Esto es muy positivo por sus potencialidades hacia la generación de valor público en la esfera local, pero marca un desafío enorme que dicha movilización no se estrelle con problemas formales de la institucionalidad colombiana. En un contexto como el actual, en espera del posconflicto, la participación política, social y ciudadana tienen un centro fundamental en el debate colombiano: si con la paz se busca crear las condiciones para consolidar la democracia en el territorio, los espacios de participación ciudadana deberían intentar dar la talla ante las nuevas circunstancias. Aunque aún queda mucho por hacer en esta vía, este trabajo pretende hacer aportes sobre este tema y entregar materiales para la discusión.

\section{Referencias}

Blanco, I., \& Gomà, R. (Coords.). (2002). Proximidad y Participación: marco conceptual y presentación de experiencias. En, Gobiernos locales y redes participativas (pp. 21-42). Barcelona: Ariel Social.

Brugué, J., \& Gallego, R. (2007). ¿Una administración pública democrática? En J. Font (Coord.), Ciudadanos y decisiones públicas (pp. 43-60). Barcelona: Ariel Ciencia Política.

Campbell, T. (2003). The Quiet Revolution: Decentralization and the Rise of Political 
Participation in Latin American Cities. Pittsburgh: University of Pittsburgh Press.

Ceballos, M., \& Martín, G. (2001). Participación $y$ fortalecimiento institucional a nivel local en Colombia. Bogotá: Centro Editorial Javeriano.

Colombia Líder. (2011). Premio a los mejor alcaldes y gobernadores 2008-2011. Recuperado de http://www.semana.com/ premio-colombia-lider-2011/index.html

Constitución Política de Colombia. (1991). Congreso de la República de Colombia. Colombia.

Del Campo, E. (2006). Gobernabilidad y descentralización político-administrativa en los países andinos. El caso de Bolivia, Ecuador. Barcelona: Documentos CIDOB.

DepartamentoAdministrativo Nacional-[DANE]. (2010). Censo 2005 - Proyecciones 19852020. Bogotá: Autor.

Departamento Nacional de Planeación -[DNP]. (2007a). El papel de los Consejos Territoriales de Planeación (CTP). Bogotá: DNP. Recuperado de https://colaboracion.dnp. gov.co/CDT/Consejo $\% 20$ Nacional $\% 20$ de $\% 20$ Planeacin/Guia $\% 20$ Consejos $\% 20$ Territoriales\%20web.pdf

Departamento Nacional de Planeación -[DNP]. (2007b). Fortalecer la descentralización $y$ adecuar el ordenamiento territorial. Propuesta para discusión. Bogotá: DNP. Recuperado de http://gidrot.com/ materials/docs/pyo/pyo19.pdf

Departamento Nacional de Planeación -[DNP]. (2007c) Informe de Desempeño Municipal. Bogotá: DNP.

Departamento Nacional de Planeación -[DNP]. (2008). Informe de Desempeño Municipal. Bogotá: DNP.
Departamento Nacional de Planeación -[DNP]. (2009). Informe de Desempeño Municipal. Bogotá: DNP.

Departamento Nacional de Planeación -[DNP]. (2010). Informe de Desempeño Municipal. Bogotá: DNP.

Entregada la credencial de la Alcaldía de Ciénaga. (23 de noviembre del 2011). El Tiempo. Recuperado de http://www. eltiempo.com/archivo/documento/

MAM-4982477

Falleti, T. G. (2010). Decentralization and subnational politics in Latin America. Cambridge: Cambridge University Press.

Font, J. (2007). Ciudadanos y decisiones públicas. Barcelona: Ariel Ciencia Política.

Grindle, M. S. (2007). Going Local. Decentralization, Democratization and the Promise of Good Governance. Princeton: Princeton University Press.

Güemes, M. C., \& Hernández-Bonivento, J. (2014). Confianza, instituciones informales y políticas públicas, una compleja relación pendular. Gestión $y$ Análisis de Políticas Públicas, 12. Recuperado de http://www.redalyc.org/ pdf/2815/281532956007.pdf

Helmke, G., \& Levitsky, S. (2004). Informal Institutions and Comparative Politics: a research agenda. Perspectives on Politics, 2(4), 725-740. doi: 10.1017/ S1537592704040472

Hernández-Bonivento, J. (2012). Instituciones informales y Reforma del Estado: Análisis al proceso de descentralización en Colombia. Grupo de Investigación en Gobierno, Administración y Políticas Públicas -[GIGAPP], Working Paper No. WP-2012-18). Recuperado de http:// 
www.gigapp.org/administrator/components/com_jresearch/files/publications/ WP-2012-18.pdf

Ley 152 de 1994. Por la cual se establece la Ley Orgánica del Plan de Desarrollo. Diario Oficial No. 41.450. Congreso de la República de Colombia, julio de 1994.

Ley 338 de 1997. Por la cual se modifica la Ley 9 de 1989, y la Ley 2 de 1991 y se dictan otras disposiciones. Diario Oficial No. 43.091. Congreso de la República de Colombia, julio de 1997.

Ley 489 de 1998. Por la cual se dictan normas sobre la organización y funcionamiento de las entidades del orden nacional, se expiden las disposiciones, principios $\mathrm{y}$ reglas generales para el ejercicio de las atribuciones previstas en los numerales 15 y 16 del artículo 189 de la Constitución Política y se dictan otras disposiciones. Diario Oficial No. 43.464. Congreso de la República de Colombia, diciembre de 1998.

Ley 1757 de 2015. Por la cual se dictan disposiciones en materia de promoción y protección del derecho a la participación democrática. Diario Oficial No. 49.565. Congreso de la República de Colombia, julio de 2015.

Maldonado, A. (2011). Los límites de la descentralización territorial: el caso de Colombia 1991-2008 (Tesis doctoral). Universidad Complutense de Madrid, Madrid. Recuperado de http://eprints. ucm.es/16363/1/T33924.pdf

Misión de Observación Electoral -[MOE]. (2011). Mapas y factores de riesgo electoral: elecciones locales y regionales, octubre 2011. Bogotá: MOE.

Misión de Observación Electoral -[MOE]. (2015). Análisis ley de Participación.
Recuperado de http://nuevo.moe.org.co/ reformas-politicas-y-electorales/estatutoparticipacion-ciudadana/451-analisisley-de-participacion.html

North, D. C. (1993). Instituciones, cambio institucional y desempeño económico. México: Fondo de Cultura Económica.

Ruano, J. M. (2010). Contra la participación: discurso y realidad de las experiencias de participación ciudadana. Politica $y$ Sociedad, 47(3), 93-108.

Scharpf, F. W. (1994). Games real actors could play: positive and negative coordination in embedded negotiations. Journal of Theoretical Politics, 6, 27-53. doi: 10.1177/0951692894006001002.

Sentencia C-524 (2003, julio 01). Acción de inconstitucionalidad. M. P. Jaime Córdoba Triviño. Corte Constitucional.

Subirats, J. (2007). Nuevos mecanismos de participación y democracia: promesas y amenazas. En J. Font (Coord.), Ciudadanos y decisiones públicas ( $\mathrm{pp}$. 33-42). Barcelona: Ariel Ciencia Política.

Transparencia por Colombia. (2010). Índice de Transparencia Municipal. Bogotá: Autor.

Velásquez, F., \& González, E. (2003). ¿Qué ha pasado con la participación ciudadana en Colombia? Bogotá: Fundación Corona. 
ANÁLISIS DE MECANiSMOS DE PARTICIPACIÓN LOCAL EN COLOMBIA:

Anexo 1

\begin{tabular}{|c|c|c|c|c|c|}
\hline & FECHA & SECTOR & DEDICACIÓN - PERFIL & LUGAR DE ENTREVISTA & DURACIÓN \\
\hline 1 & $\begin{array}{l}6 \text { de marzo de } \\
2012\end{array}$ & Experto & $\begin{array}{l}\text { Profesional Dirección Nacional de } \\
\text { Planeación }\end{array}$ & $\begin{array}{l}\text { Bogotá, Distrito Capital, } \\
\text { Colombia }\end{array}$ & $39 m-26 s$ \\
\hline 2 & $\begin{array}{l}7 \text { de marzo de } \\
2012\end{array}$ & Experto & $\begin{array}{l}\text { Académica Pontificia Universidad } \\
\text { Javeriana }\end{array}$ & $\begin{array}{l}\text { Bogotá, Distrito Capital, } \\
\text { Colombia }\end{array}$ & $31 \mathrm{~m}-50 \mathrm{~s}$ \\
\hline 3 & $\begin{array}{l}7 \text { de marzo de } \\
2012\end{array}$ & Experto & $\begin{array}{l}\text { Federación Colombiana de } \\
\text { Municipios }\end{array}$ & $\begin{array}{l}\text { Bogotá, Distrito Capital, } \\
\text { Colombia }\end{array}$ & $34 \mathrm{~m}-31 \mathrm{~s}$ \\
\hline 4 & $\begin{array}{l}7 \text { de marzo de } \\
2012\end{array}$ & Experto & $\begin{array}{l}\text { Federación Colombiana de } \\
\text { Municipios }\end{array}$ & $\begin{array}{l}\text { Bogotá, Distrito Capital, } \\
\text { Colombia }\end{array}$ & $34 \mathrm{~m}-31 \mathrm{~s}$ \\
\hline 5 & $\begin{array}{l}8 \text { de marzo de } \\
2012\end{array}$ & Experto & $\begin{array}{l}\text { Académico Universidad Externado } \\
\text { de Colombia }\end{array}$ & $\begin{array}{l}\text { Bogotá, Distrito Capital, } \\
\text { Colombia }\end{array}$ & $50 \mathrm{~m}-00 \mathrm{~s}$ \\
\hline 6 & $\begin{array}{l}12 \text { de marzo } \\
\text { de } 2012\end{array}$ & $\begin{array}{l}\text { Funcionario } \\
\text {-Contratista }\end{array}$ & $\begin{array}{l}\text { Alcaldía de Facatativá -Secretaria } \\
\text { de Relaciones Interinstitucionales }\end{array}$ & $\begin{array}{l}\text { Facatativá, Cundinamarca, } \\
\text { Colombia }\end{array}$ & $21 \mathrm{~m}-33 \mathrm{~s}$ \\
\hline 7 & $\begin{array}{l}12 \text { de marzo } \\
\text { de } 2012\end{array}$ & $\begin{array}{l}\text { Funcionario - } \\
\text { Contratista }\end{array}$ & $\begin{array}{l}\text { Exfuncionario Alcaldía de } \\
\text { Facatativá - Sector Salud }\end{array}$ & $\begin{array}{l}\text { Facatativá, Cundinamarca, } \\
\text { Colombia }\end{array}$ & $19 \mathrm{~m}-14 \mathrm{~s}$ \\
\hline 8 & $\begin{array}{l}12 \text { de marzo } \\
\text { de } 2012\end{array}$ & $\begin{array}{l}\text { Organización } \\
\text { Social }\end{array}$ & $\begin{array}{l}\text { Líder local - Fundación Oasis - } \\
\text { Atención al adulto mayor }\end{array}$ & $\begin{array}{l}\text { Facatativá, Cundinamarca, } \\
\text { Colombia }\end{array}$ & $30 \mathrm{~m}-36 \mathrm{~s}$ \\
\hline 9 & $\begin{array}{l}14 \text { de marzo } \\
\text { de } 2012\end{array}$ & СТP & $\begin{array}{l}\text { Presidente Consejo Territorial de } \\
\text { Planeación }\end{array}$ & $\begin{array}{l}\text { Facatativá, Cundinamarca, } \\
\text { Colombia }\end{array}$ & $21 \mathrm{~m}-29 \mathrm{~s}$ \\
\hline 10 & $\begin{array}{l}14 \text { de marzo } \\
\text { de } 2012\end{array}$ & CTP & $\begin{array}{l}\text { Consejeros Territoriales de } \\
\text { Planeación }\end{array}$ & $\begin{array}{l}\text { Facatativá, Cundinamarca, } \\
\text { Colombia }\end{array}$ & $29 \mathrm{~m}-25 \mathrm{~s}$ \\
\hline 11 & $\begin{array}{l}15 \text { de marzo } \\
\text { de } 2012\end{array}$ & $\begin{array}{l}\text { Funcionario - } \\
\text { Contratista }\end{array}$ & $\begin{array}{l}\text { Alcaldía de Facatativá - } \\
\text { Subsecretario de Obras Públicas }\end{array}$ & $\begin{array}{l}\text { Facatativá, Cundinamarca, } \\
\text { Colombia }\end{array}$ & $24 m-56 s$ \\
\hline 12 & $\begin{array}{l}15 \text { de marzo } \\
\text { de } 2012\end{array}$ & $\begin{array}{l}\text { Funcionario - } \\
\text { Contratista }\end{array}$ & $\begin{array}{l}\text { Alcaldía de Facatativá - Secretario } \\
\text { de Educación }\end{array}$ & $\begin{array}{l}\text { Facatativá, Cundinamarca, } \\
\text { Colombia }\end{array}$ & $18 \mathrm{~m}-17 \mathrm{~s}$ \\
\hline 13 & $\begin{array}{l}15 \text { de marzo } \\
\text { de } 2012\end{array}$ & $\begin{array}{l}\text { Organización } \\
\text { Social }\end{array}$ & $\begin{array}{l}\text { Fundación Restrepo-Millán } \\
\text { Educare }\end{array}$ & $\begin{array}{l}\text { Facatativá, Cundinamarca, } \\
\text { Colombia }\end{array}$ & $23 \mathrm{~m}-49 \mathrm{~s}$ \\
\hline 14 & $\begin{array}{l}15 \text { de marzo } \\
\text { de } 2012\end{array}$ & $\begin{array}{l}\text { Organización } \\
\text { Social }\end{array}$ & $\begin{array}{l}\text { Fundación Restrepo-Millán } \\
\text { Educare }\end{array}$ & $\begin{array}{l}\text { Facatativá, Cundinamarca, } \\
\text { Colombia }\end{array}$ & $23 \mathrm{~m}-49 \mathrm{~s}$ \\
\hline 15 & $\begin{array}{l}15 \text { de marzo } \\
\text { de } 2012\end{array}$ & $\begin{array}{l}\text { Funcionario - } \\
\text { Contratista }\end{array}$ & $\begin{array}{l}\text { Alcaldía de Facatativá - Secretaria } \\
\text { de Desarrollo Social }\end{array}$ & $\begin{array}{l}\text { Facatativá, Cundinamarca, } \\
\text { Colombia }\end{array}$ & $32 \mathrm{~m}-48 \mathrm{~s}$ \\
\hline 16 & $\begin{array}{l}20 \text { de marzo } \\
\text { de } 2012\end{array}$ & $\begin{array}{l}\text { Funcionario - } \\
\text { Contratista }\end{array}$ & $\begin{array}{l}\text { Alcaldía de Facatativá - Secretario } \\
\text { de Obras Públicas }\end{array}$ & $\begin{array}{l}\text { Facatativá, Cundinamarca, } \\
\text { Colombia }\end{array}$ & $20 \mathrm{~m}-45$ \\
\hline 17 & $\begin{array}{l}20 \text { de marzo } \\
\text { de } 2012\end{array}$ & $\begin{array}{l}\text { Organización } \\
\text { Social }\end{array}$ & $\begin{array}{l}\text { Comité de Discapacidad de } \\
\text { Facatativá }\end{array}$ & $\begin{array}{l}\text { Facatativá, Cundinamarca, } \\
\text { Colombia }\end{array}$ & $13 \mathrm{~m}-41 \mathrm{~s}$ \\
\hline 18 & $\begin{array}{l}20 \text { de marzo } \\
\text { de } 2012\end{array}$ & $\begin{array}{l}\text { Organización } \\
\text { Social }\end{array}$ & $\begin{array}{l}\text { Comité de Discapacidad de } \\
\text { Facatativá }\end{array}$ & $\begin{array}{l}\text { Facatativá, Cundinamarca, } \\
\text { Colombia }\end{array}$ & $13 \mathrm{~m}-41 \mathrm{~s}$ \\
\hline 19 & $\begin{array}{l}21 \text { de marzo } \\
\text { de } 2012\end{array}$ & $\begin{array}{l}\text { Funcionario - } \\
\text { Contratista }\end{array}$ & $\begin{array}{l}\text { Alcaldía de Facatativá - Secretario } \\
\text { de Salud }\end{array}$ & $\begin{array}{l}\text { Facatativá, Cundinamarca, } \\
\text { Colombia }\end{array}$ & $37 \mathrm{~m}-18 \mathrm{~s}$ \\
\hline 20 & $\begin{array}{l}21 \text { de marzo } \\
\text { de } 2012\end{array}$ & $\begin{array}{l}\text { Organización } \\
\text { Social }\end{array}$ & $\begin{array}{l}\text { Fundación Nueva Vida - Atención a } \\
\text { drogodependientes }\end{array}$ & $\begin{array}{l}\text { Facatativá, Cundinamarca, } \\
\text { Colombia }\end{array}$ & $16 \mathrm{~m}-06$ \\
\hline 21 & $\begin{array}{l}26 \text { de marzo } \\
\text { de } 2012\end{array}$ & $\begin{array}{l}\text { Funcionario - } \\
\text { Contratista }\end{array}$ & Exalcalde de Facatativá 2008-2011 & $\begin{array}{l}\text { Bogotá, Distrito Capital, } \\
\text { Colombia }\end{array}$ & $26 \mathrm{~m}-40 \mathrm{~s}$ \\
\hline 22 & $\begin{array}{l}29 \text { de marzo } \\
\text { de } 2012\end{array}$ & $\begin{array}{l}\text { Funcionario - } \\
\text { Contratista }\end{array}$ & $\begin{array}{l}\text { Exfuncionario y exalcalde } \\
\text { encargado de Ciénaga }\end{array}$ & $\begin{array}{l}\text { Santa Marta, Magdalena, } \\
\text { Colombia }\end{array}$ & $42 \mathrm{~m}-27 \mathrm{~s}$ \\
\hline 23 & $\begin{array}{l}4 \text { de abril de } \\
2012\end{array}$ & $\begin{array}{l}\text { Organización } \\
\text { Social }\end{array}$ & $\begin{array}{l}\text { Grupo de Acción Social - Atención } \\
\text { a Víctimas del Conflicto }\end{array}$ & Ciénaga, Magdalena, Colombia & $12 \mathrm{~m}-34 \mathrm{~s}$ \\
\hline 24 & $\begin{array}{l}4 \text { de abril de } \\
2012\end{array}$ & $\begin{array}{l}\text { Funcionario - } \\
\text { Contratista }\end{array}$ & $\begin{array}{l}\text { Alcaldía de Ciénaga - Jefe de la } \\
\text { Oficina de Planeación }\end{array}$ & Ciénaga, Magdalena, Colombia & $38 \mathrm{~m}-41 \mathrm{~s}$ \\
\hline
\end{tabular}




\begin{tabular}{|c|c|c|c|c|c|}
\hline & FECHA & SECTOR & DEDICACIÓN - PERFIL & LUGAR DE ENTREVISTA & DURACIÓN \\
\hline 25 & $\begin{array}{l}4 \text { de abril de } \\
2012\end{array}$ & $\begin{array}{l}\text { Funcionario - } \\
\text { Contratista }\end{array}$ & $\begin{array}{l}\text { Alcaldía de Ciénaga - Secretario de } \\
\text { Educación }\end{array}$ & Ciénaga, Magdalena, Colombia & $38 \mathrm{~m}-41 \mathrm{~s}$ \\
\hline 26 & $\begin{array}{l}9 \text { de abril de } \\
2012\end{array}$ & $\begin{array}{l}\text { Organización } \\
\text { Social }\end{array}$ & $\begin{array}{l}\text { Rector Instituto Nacional de } \\
\text { Formación Técnica Profesional } \\
\text { INFOTEP }\end{array}$ & Ciénaga, Magdalena, Colombia & $19 m-36 s$ \\
\hline 27 & $\begin{array}{l}10 \text { de abril de } \\
2012\end{array}$ & $\begin{array}{l}\text { Funcionario - } \\
\text { Contratista }\end{array}$ & Edil del Municipio de Ciénaga & Ciénaga, Magdalena, Colombia & $12 \mathrm{~m}-28 \mathrm{~s}$ \\
\hline 28 & $\begin{array}{l}11 \text { de abril de } \\
2012\end{array}$ & $\begin{array}{l}\text { Funcionario - } \\
\text { Contratista }\end{array}$ & $\begin{array}{l}\text { Consultora - Académica } \\
\text { Universidad del Magdalena }\end{array}$ & Ciénaga, Magdalena, Colombia & $26 \mathrm{~m}-57 \mathrm{~s}$ \\
\hline 29 & $\begin{array}{l}11 \text { de abril de } \\
2012\end{array}$ & $\begin{array}{l}\text { Organización } \\
\text { Social }\end{array}$ & $\begin{array}{l}\text { Académico - Universidad del } \\
\text { Magdalena }\end{array}$ & Ciénaga, Magdalena, Colombia & $26 \mathrm{~m}-57 \mathrm{~s}$ \\
\hline 30 & $\begin{array}{l}17 \text { de abril de } \\
2012\end{array}$ & CTP & $\begin{array}{l}\text { Presidente Consejo Territorial de } \\
\text { Planeación }\end{array}$ & Ciénaga, Magdalena, Colombia & $27 \mathrm{~m}-10 \mathrm{~s}$ \\
\hline 31 & $\begin{array}{l}2 \text { de } \\
\text { noviembre } \\
2012\end{array}$ & $\begin{array}{l}\text { Funcionario - } \\
\text { Contratista }\end{array}$ & $\begin{array}{l}\text { Departamento Administrativo de la } \\
\text { Función Pública }\end{array}$ & $\begin{array}{l}\text { Bogotá, Distrito Capital, } \\
\text { Colombia }\end{array}$ & $22 \mathrm{~m}-04 \mathrm{~s}$ \\
\hline 32 & $\begin{array}{l}2 \text { de } \\
\text { noviembre } \\
2012\end{array}$ & $\begin{array}{l}\text { Funcionario - } \\
\text { Contratista }\end{array}$ & $\begin{array}{l}\text { Departamento Administrativo de la } \\
\text { Función Pública }\end{array}$ & $\begin{array}{l}\text { Bogotá, Distrito Capital, } \\
\text { Colombia }\end{array}$ & $22 \mathrm{~m}-04 \mathrm{~s}$ \\
\hline 33 & $\begin{array}{l}29 \text { de marzo } \\
\text { de } 2012\end{array}$ & $\begin{array}{l}\text { Organización } \\
\text { Social }\end{array}$ & $\begin{array}{l}\text { Miembro del Partido Polo } \\
\text { Democrático }\end{array}$ & $\begin{array}{l}\text { Santa Marta, Magdalena, } \\
\text { Colombia }\end{array}$ & Sin grabación \\
\hline 34 & $\begin{array}{l}30 \text { de marzo } \\
\text { de } 2012\end{array}$ & $\begin{array}{l}\text { Organización } \\
\text { Social }\end{array}$ & $\begin{array}{l}\text { Líder Comunitario - Fundación } 6 \text { de } \\
\text { diciembre }\end{array}$ & Ciénaga, Magdalena, Colombia & Sin grabación \\
\hline 35 & $\begin{array}{l}4 \text { de abril de } \\
2012\end{array}$ & $\begin{array}{l}\text { Funcionario - } \\
\text { Contratista }\end{array}$ & $\begin{array}{l}\text { Exfuncionario - Jefe de Oficina de } \\
\text { Planeación }\end{array}$ & $\begin{array}{l}\text { Santa Marta, Magdalena, } \\
\text { Colombia }\end{array}$ & Sin grabación \\
\hline 36 & $\begin{array}{l}11 \text { de abril de } \\
2012\end{array}$ & $\begin{array}{l}\text { Organización } \\
\text { Social }\end{array}$ & $\begin{array}{l}\text { Académico - Universidad del } \\
\text { Magdalena }\end{array}$ & $\begin{array}{l}\text { Santa Marta, Magdalena, } \\
\text { Colombia }\end{array}$ & Sin grabación \\
\hline 37 & $\begin{array}{l}17 \text { de abril de } \\
2012\end{array}$ & CTP & $\begin{array}{l}\text { Profesor INFOTEP - Consejo } \\
\text { Territorial de Planeación }\end{array}$ & Ciénaga, Magdalena, Colombia & Sin grabación \\
\hline
\end{tabular}

Fuente: elaboración propia. 